\title{
THE INTERACTION OF COMPETITION AND FOOD SUPPLY IN TWO LINES OF DROSOPHILA MELANOGASTER
}

\author{
M. J. KEARSEY \\ A.R.C. Unit of Biometrical Genetics \\ Department of Genetics, University of Birmingham
}

\section{INTRODUCTION}

Received 9.xi.64

COMPETITION has been extensively studied on account of both its evolutionary significance and its importance in plant and animal populations. However, interpretation of such work has often proved difficult because of the attempt to study the phenomenon under conditions where the competitive situation is complex. For instance, the work of Park (1948) with flour beetles covered all stages in the life cycle of the competing individuals over several generations. In such a situation there will be competition for food, mates, laying space, etc., together with pure culture differences and effects such as cannibalism. Many plant experiments are equally complex.

Important as such investigations are it is considered that an attempt to study a simple competitive situation might be useful as a first step towards exploring competition at a population level. The present work is an examination of such a simple case, during the larval stage of Drosophila melanogaster. The larval stage of $D$. melanogaster is relatively short at $25^{\circ} \mathrm{C}$., lasting between 4 and 7 days, depending on the amount of food supplied. Earlier experiments have suggested that during this stage the larvæ are mainly involved in feeding and moulting, and hence competition between individuals is likely to be for food alone.

As the term " competition" has been variously used by different authors, it is necessary to explain its meaning as used in the present text. The definition suggested by Milne ( $196 \mathrm{r}$ ) has been adopted: that "Competition is the endeavour of two (or more) individuals to gain the same particular thing, or to gain the measure each wants from a supply of a thing when that supply is not sufficient for both (or all)". The important factor to emphasise in this definition is the necessity for some resource to be in short supply.

Irrespective of the intensity of competition, however, its effect will not necessarily be apparent for example in a situation where the competing individuals are of equal ability; the outcome will then depend on chance alone. In order to demonstrate the effects of competition two requirements must thus be fulfilled. The competing individuals must differ in their ability to obtain the resource, and a suitable character must be found, the manifestation of which is affected 
by the limiting resource. In the present work the resource being limited is the larval food supply in the form of killed bakers' yeast. The character affected is viability, measured as the proportion of larvæ either pupating or becoming adults. Two lines of Drosophila were used which differed in their ability to obtain yeast, this difference probably reflecting a difference in feeding rate (see Bakker, I96r).

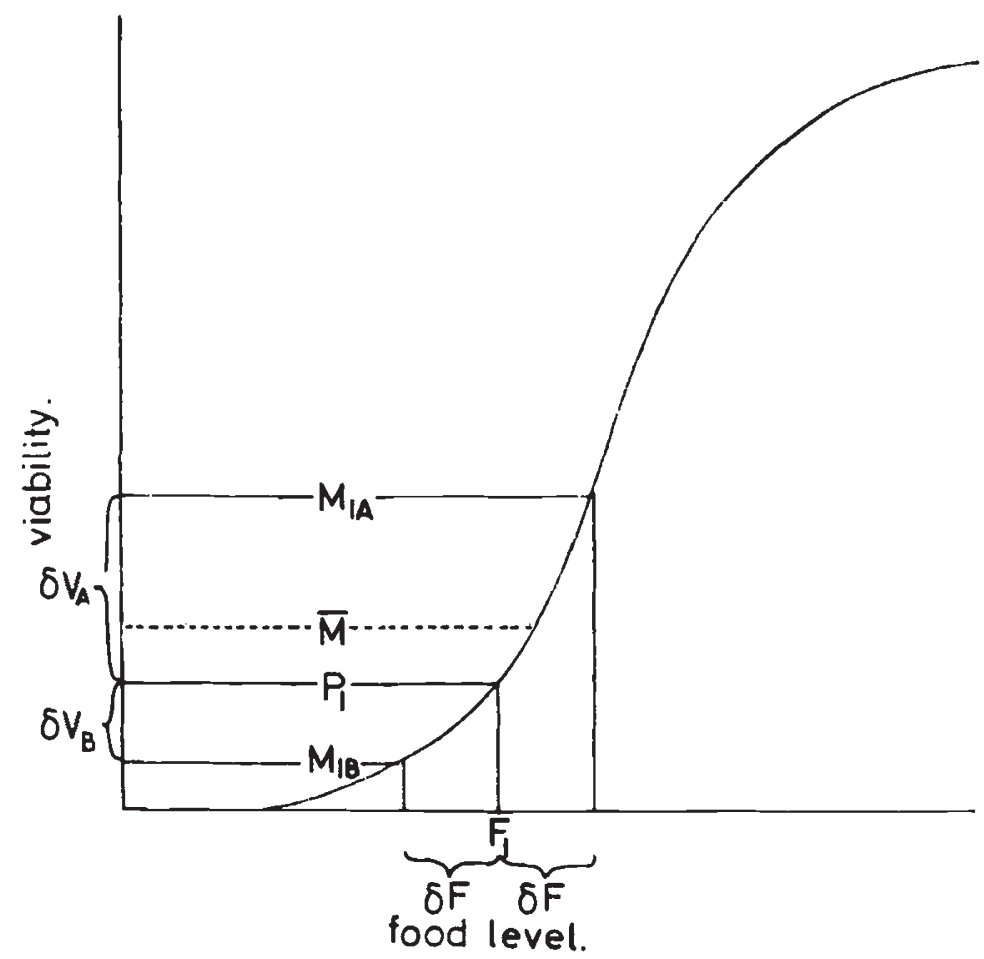

FIG. 1.-To illustrate the point that, although one line gains and the other line loses the same amount of food $(\delta F)$ through competition, the actual change in viability $(\delta \mathrm{V})$ of the two lines will not necessarily be of the same magnitude.

If we assume that these differences in larval competitive ability are caused by differences in feeding rate, it should be possible to predict the outcome of competition once the feeding rates are known. Bakker (I96r) devised a method of estimating the time taken for the larvæ of his two competing strains to pupate, and showed the stronger competitor to be some 3 hours quicker in this respect. This method has been tried unsuccessfully in earlier experiments here, but it may not be the best measure of feeding rate. What is important in a competition experiment, however, is not so much the absolute values of the feeding rates, as the difference between them. In the present work the difference has been measured in terms of the extra food gained or lost by the stronger or weaker competitor respectively, and has been estimated in the following way.

When a number of larvæ of like genotype are presented with a 
fixed weight of yeast, the average amount of food available to each larva can be calculated, and the viability of the line at this food level observed. If the viabilities are plotted over a range of decreasing food levels it is found that the character does not alter until quite a low food level is reached. Below this level, however, viability falls
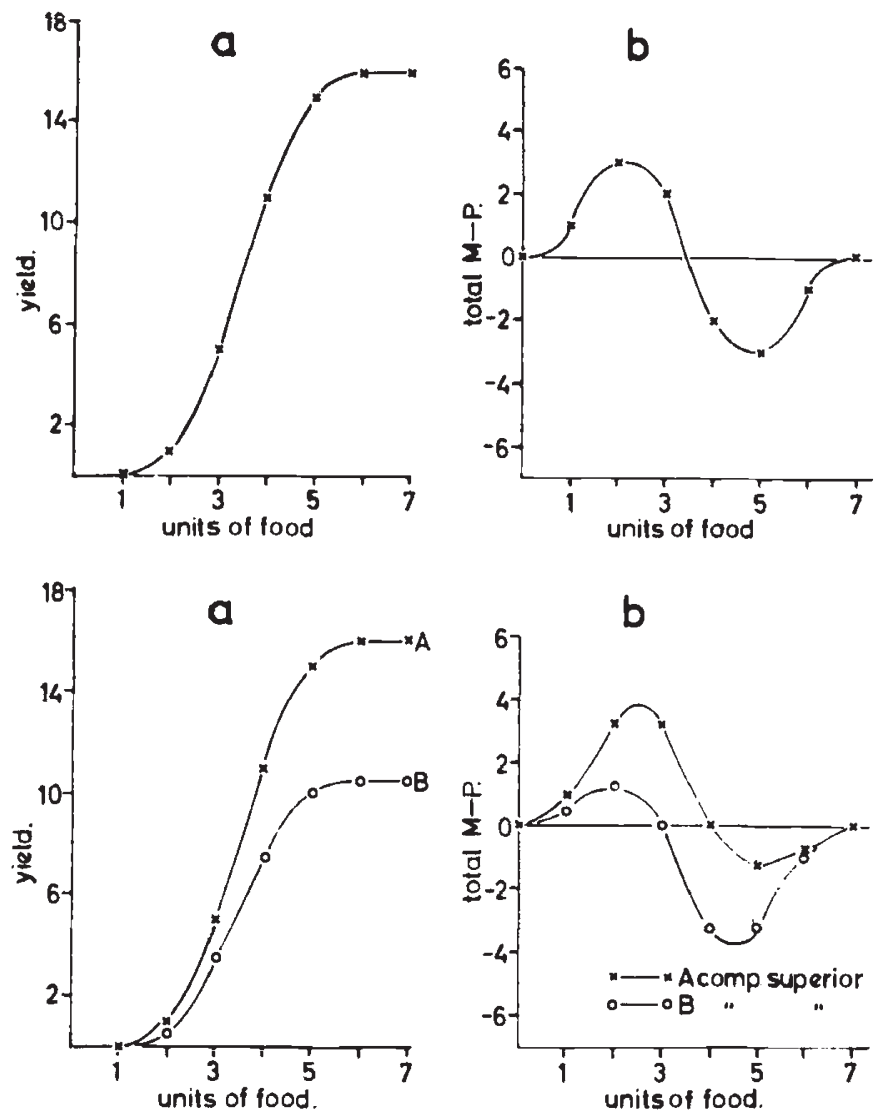

FIG, 2.- Theoretical relationships between the critical food ranges and maximum viabilities of two competing lines $(a)$, and the predicted difference between the total yields of mixed and pure cultures at the various food levels $(b)$. Upper graphs-both competing lines having the same critical food range and maximum viabilities.

Lower graphs-both competing lines having the same critical food range but different maximum viabilities.

rapidly to zero in a sigmoid curve. This effect was also shown by Bakker (1961). The range of food levels over which viability falls from a maximum to zero will be referred to as the critical range, and the sigmoid graph of viabilities over this range, the critical curve. It is reasonable to expect that above this range competition will not affect viability since the food resource is no longer limiting.

If the critical curve is known for any line, it follows conversely that the food level can be estimated from the observed viability. So if a known density of larvæ consisting of equal numbers from two lines is presented with a food level within the critical range, it is possible to 
calculate the average amount of food available to each larva, and also, by observing the viabilities of the two lines, the average amount of food actually taken up per larva in each line. The difference between the observed and expected uptake of food by each line represents the
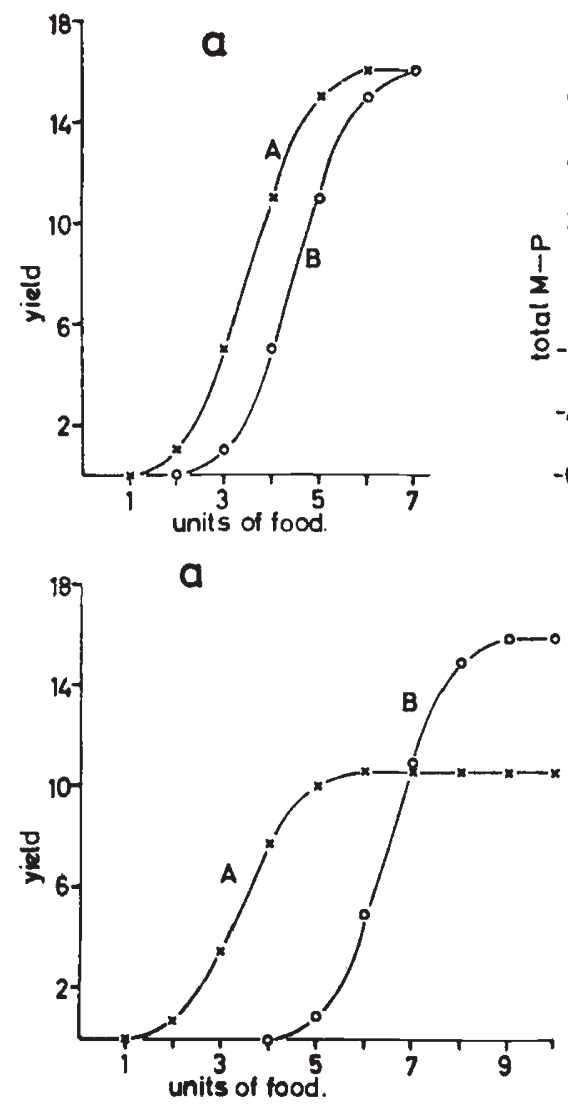

b

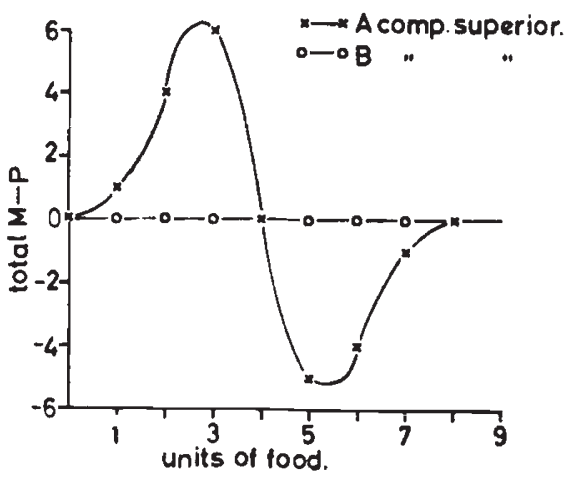

b

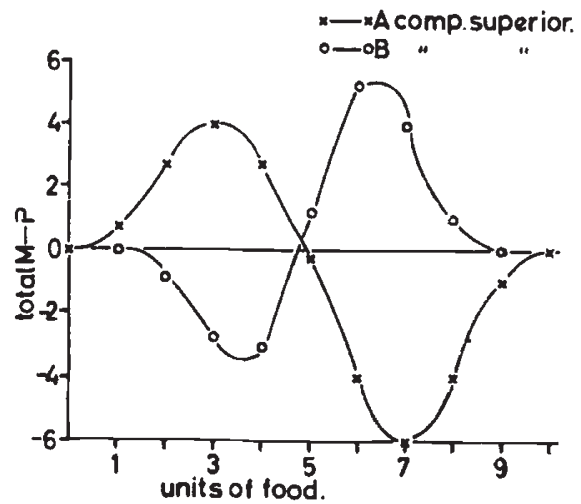

FIG. 3.- Theoretical relationships between the critical food ranges and maximum viabilities of two competing lines $(a)$, and the predicted difference between the total yields of mixed and pure cultures at the various food levels $(b)$.

Upper graphs-The competing lines having their critical ranges displaced along the abscissa by an amount equal to $\delta \mathrm{F}$, the extra food gained or lost by a single individual of the competing line, the maximum viabilities being the same. Lower graphs-The competing lines having their critical food ranges displaced along the abscissa, the line with the higher maximum viability having the higher critical food range.

amount of food gained or lost by the stronger or weaker competitor respectively. In preliminary experiments this gain (or loss) was found to be approximately one-fifth of the critical range.

It follows then that knowing the value of this gain (or loss) of food by either line at one food level it should be possible to predict the yields of both lines in mixed culture at any other food level. This of course assumes that the gain (or loss) will be the same irrespective of the food level. Such an assumption is probably not strictly valid but, as will be suggested later, it is likely to be a sufficiently good 
approximation in the present case. Now let us consider what the outcome of competition will be if this relation holds good. For this purpose we shall describe a case in which both competing lines ( $A$ and B) have the same critical curves, and that $\mathrm{A}$ is competitively superior (fig. I). At a low food level, $F_{1}$, the viability of both lines is $P_{1}$ in pure culture. In a mixed culture containing equal numbers of both lines, $A$ will gain, and $B$ lose $\delta F$ units of food, and their mixed culture, viabilities will thus be $\mathrm{M}_{1 \mathrm{~A}}$ and $\mathrm{M}_{1 \mathrm{~B}}$ respectively. Since the critical curve is sigmoid, the increase in viability of $A\left(\delta V_{A}\right)$ is greater at lower food levels than is the decrease in viability of $B\left(\delta V_{B}\right)$ and the average mixed culture viability $(\bar{M})$ is consequently greater than $P_{1}$, i.e. $\mathrm{M}-\mathrm{P}>0$. At a food level at the upper part of the critical range, $\delta \mathrm{V}_{\mathrm{A}}$ will be less than $\delta V_{B}$ and $M-P<0$. If the $M-P$ values are plotted against the food supply, they will follow a cubic relationship as shown in fig. 2 (upper graph).

It is likely in practice that the critical ranges of the two lines 'will differ, and will their maximum viabilities also. Such situations produce similar results, however, and these together with the above cases are shown graphically in figs. 2 and 3 .

The object of the present experiment was to test this prediction, by demonstrating a cubic relationship between M-P values and food level over the critical range.

\section{MATERIALS AND TECHNIQUES}

A wild type and a vestigial line were used in the experiments. The wild type was line 2 described by Mather and Cooke ( 1962 ), being an inbred line consisting of Oregon chromosomes X and II and Samarkand chromosome III. The vestigial line, vg6, was obtained from Professor Thoday of the University of Cambridge, where it had been selected for a high number of sternopleural chaetæ. It has been subsequently inbred in this laboratory for twenty generations.

A modification of the method described by Bakker ( 1961 ) was used to obtain a large number of eggs of the same age. Thirty females, together with males, were allowed to lay in a tube containing normal yeasted oatmeal medium for 3 days. By this time sufficient larvæ had emerged to inhibit further laying, and the females began to store eggs. When the females were presented with a suitable oviposition medium these eggs were released rapidly to produce 200 to 400 eggs per tube in a 2-hour period. The laying surface consisted of a plastic stick which was coated with a starch paste blackened with charcoal, and which fitted into the laying tube. The paste was prepared by heating $34 \mathrm{gm}$. of starch in $240 \mathrm{ml}$. of water together with sufficient charcoal to colour it. As the mixture thickened the sticks were dipped into it, removed and allowed to cool. The sticks were then placed in the laying tubes and held in position by the yeasted food cake, the females being introduced without etherising.

After the females had been in the laying tubes for about 2 hours, the sticks were removed, and the eggs transferred to petri dishes containing agar. They were incubated at $25^{\circ} \mathrm{C}$. and hatched in about 22 hours. The emergent larva were collected and transferred to the experimental tubes by means of a micro-spatula, care being taken not to transfer any larvæ which had developed in vivo. The latter can easily be distinguished by their much larger size.

The larvæ were fed on an agar-yeast medium consisting of $20 \mathrm{gm}$. Spanish agar, Io gm. of dried bakers' yeast (pure yeast powder) and $10 \mathrm{ml}$. of $\mathrm{io}$ per cent. nipagin 
in a litre of water, i.e. $\mathrm{I} \mathrm{ml}$. of medium $\equiv \mathrm{I}$ o mgm. yeast. Because the yeast remains as a precipitate care had to be taken in pouring the medium into the experimental tubes. To overcome any bias which may result from the yeast settling out, the tubes, representing different treatments, were poured in random order. To provide the various food levels, the volume of agar-yeast medium per tube was varied. Justification of this procedure came from a preliminary experiment in which the pure culture viability of a line was measured over the whole of the critical range, at two densities, 50 and Ioo larvæ per tube. Thus at any one food level the higher density was presented with twice the volume of food given to the lower density. The critical curves were found to be the same at both densities so showing that it was the absolute amount of food per larva, and not an effect of volume per se, that was limiting survival.

In the present experiment a density of 50 larvæ per tube was used in both pure and mixed cultures. At any one food level four tubes were set up, two being pure cultures and two mixed, the latter each containing 25 larvæ of each line. It was necessary to duplicate the mixed cultures in order that there should be 50 larvæ of each line in both pure and mixed culture.

Eight food levels were used, chosen to span the critical range. These were $0.4,0.6,0.8, \ldots 1.8 \mathrm{mgm}$. yeast per larva, and hence the tubes contained 2, 3, $4, \ldots 9 \mathrm{ml}$. of medium respectively. There were thus $3^{2}$ treatments per block, and 6 blocks were set up altogether. All experiments were carried out at $25^{\circ} \mathrm{C}$.

The yield of adults was recorded from all 6 blocks but pupal yields were recorded from only 5 of them.

\section{RESULTS}

Table I shows the pure culture yields of pupæ and adults for each line.

TABLE

Tields of pupe and adults in pure culture for each line, obtained from a density of 50 larva per tube, over the critical range. (Pupal data upper line, adult data lower line)

\begin{tabular}{|c|c|c|c|c|c|c|c|c|c|c|c|c|c|c|c|c|}
\hline \multirow{2}{*}{$\begin{array}{l}\text { Food } \\
\text { level }\end{array}$} & \multicolumn{8}{|c|}{ Line 2} & \multicolumn{8}{|c|}{ Line vg6 } \\
\hline & I & 2 & 3 & 4 & 5 & 6 & Total & percent & I & 2 & 3 & 4 & 5 & 6 & Total & percent \\
\hline \multirow{2}{*}{0.4} & 0 & - & 2 & o & I & I & 4 & $1 \cdot 6$ & 0 & - & 9 & 6 & 2 & I & 18 & $7 \cdot 2$ \\
\hline & 0 & I & 0 & 0 & 0 & 0 & i & 0.3 & 0 & o & 0 & 0 & 0 & 0 & 0 & o \\
\hline \multirow[t]{2}{*}{0.6} & 5 & - & I5 & 9 & 10 & 2 & $4^{I}$ & $16 \cdot 4$ & 7 & - & 39 & 9 & 6 & 4 & 65 & $26 \cdot 0$ \\
\hline & I & 0 & 5 & 0 & 3 & 0 & 9 & $3 \cdot 0$ & 0 & 0 & IO & 2 & 3 & 0 & 15 & 5.0 \\
\hline \multirow[t]{2}{*}{0.8} & 12 & - & 20 & 7 & 7 & 3 & 49 & $19 \cdot 6$ & 19 & - & 32 & 20 & I 4 & 8 & 93 & $37 \cdot 2$ \\
\hline & 4 & I & 4 & 0 & o & 0 & 9 & $3 \cdot 0$ & 5 & 6 & 6 & 5 & 3 & 7 & $3^{2}$ & $10 \cdot 7$ \\
\hline \multirow{2}{*}{ I $\cdot O$} & 28 & - & 29 & 10 & 10 & 13 & 90 & $3^{6 \cdot 0}$ & $3^{I}$ & - & 43 & 37 & 27 & I 5 & I 53 & $6 I \cdot 2$ \\
\hline & 8 & 2 & 13 & I & I & 2 & 27 & $9 \cdot 0$ & I I & 14 & 17 & 14 & 12 & 3 & 71 & 23.7 \\
\hline \multirow{2}{*}{$\mathrm{I} \cdot 2$} & 30 & - & 39 & 35 & I 4 & 13 & I 31 & 5 & 34 & - & 40 & 35 & 35 & 31 & I 75 & $70 \cdot 0$ \\
\hline & 12 & 14 & 25 & 22 & 2 & 3 & 78 & $26 \cdot 0$ & 16 & 22 & 26 & I 3 & 12 & I 6 & 105 & $35^{\circ} \mathrm{O}$ \\
\hline \multirow{2}{*}{ I. 4} & 35 & - & $4^{2}$ & 27 & 36 & I3 & 15 & $6 \mathrm{I} \cdot 2$ & 34 & - & 4 & $4 \mathrm{I}$ & 36 & $3^{8}$ & 19 & $76 \cdot 0$ \\
\hline & 22 & 9 & $4^{1}$ & I3 & 24 & 2 & III & 37.0 & 20 & 19 & 30 & 22 & 17 & 16 & 124 & $41 \cdot 3$ \\
\hline \multirow{2}{*}{ I 6} & 36 & - & $4^{6}$ & 29 & 30 & 40 & I 81 & $72 \cdot 4$ & 36 & 一 & 44 & 43 & 33 & 44 & 200 & $80 \cdot 0$ \\
\hline & 27 & I4 & $3^{6}$ & I6 & I9 & $3^{2}$ & 144 & $4^{8 \cdot 0}$ & 19 & 22 & 18 & 24 & 12 & 22 & 117 & $39^{\circ} \mathrm{O}$ \\
\hline \multirow{2}{*}{$\mathrm{I} \cdot 8$} & 40 & - & 45 & 34 & 46 & 30 & 195 & $78 \cdot 0$ & 40 & - & 43 & $3^{8}$ & 46 & 39 & 206 & $82 \cdot 4$ \\
\hline & 30 & 25 & $4^{2}$ & 27 & $2 \mathrm{I}$ & 12 & I 57 & $52 \cdot 3$ & 36 & 22 & 28 & $2 \mathrm{I}$ & 26 & I8 & ${ }^{1} 5^{I}$ & $5^{0} \cdot 3$ \\
\hline
\end{tabular}


The critical curves of lines 2 and vg6 were plotted from the percentage viability of adults, averaged over all blocks (fig. 4). Similar curves could of course be drawn for the pupal viabilities. The relationship between the critical curves of 2 and $\mathrm{vg} 6$ is similar to that shown in fig. $3 a$ (upper graph), and hence if vg6 is the stronger competitor a graph of M-P values similar to fig. $3^{b}$ should be obtained from the data.

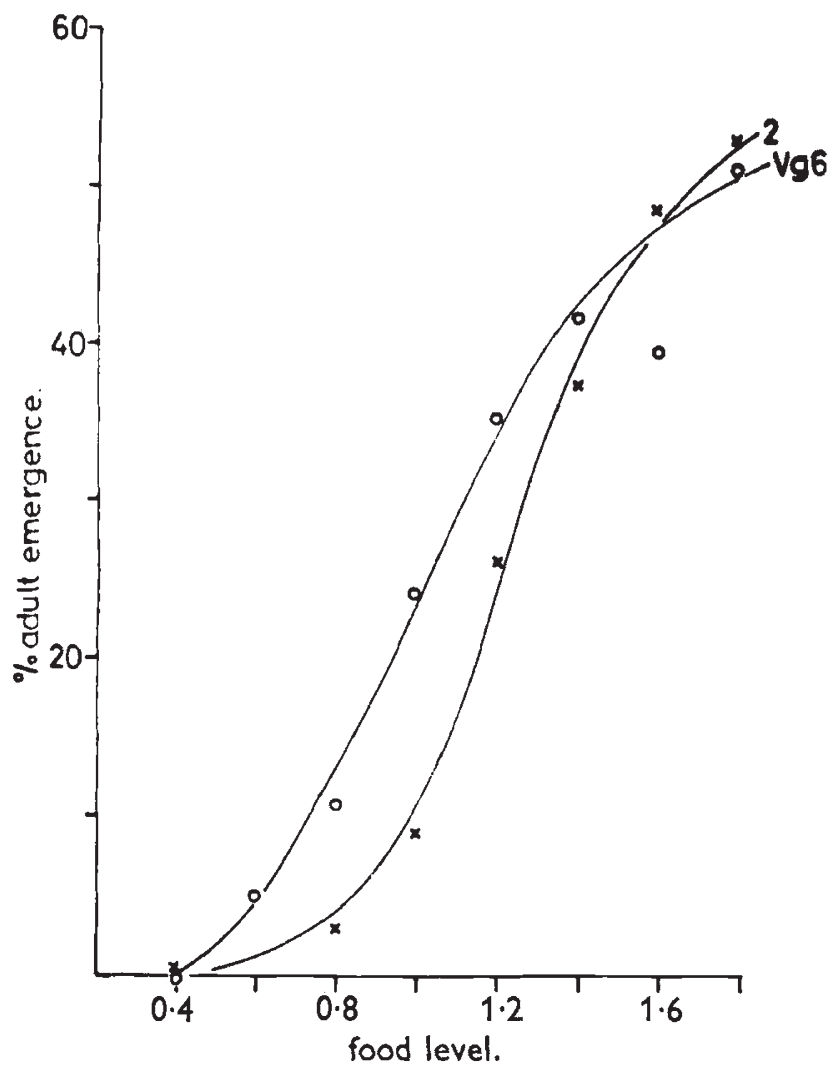

FIG. 4.-The critical curves of lines 2 and vg6 (adult viability).

The values for the difference in yield between mixed and pure culture (M-P) are shown in table 2 for both pupæ and adults.

When the total M-P values for adults and pupæ are plotted against food level (fig. 5) a cubic relationship, similar to that expected, is obtained. At very low food levels mixed cultures yield the same as pure. As the food level increases the mixed cultures outyield the pure and their supremacy rises to a maximum before falling to zero again at $\mathrm{I} \cdot 2 \mathrm{mg}$. yeast per larva. Above this food level pure cultures yield more than do mixed (i.e. M-P is negative) the M-P values reach a minimum and then increase to zero at the upper limit of the critical range.

An analysis of variance of the M-P values yields SS for the items 
TABLE 2

Total M-P values for pupe and adults. Pupe upper line, adults lower line

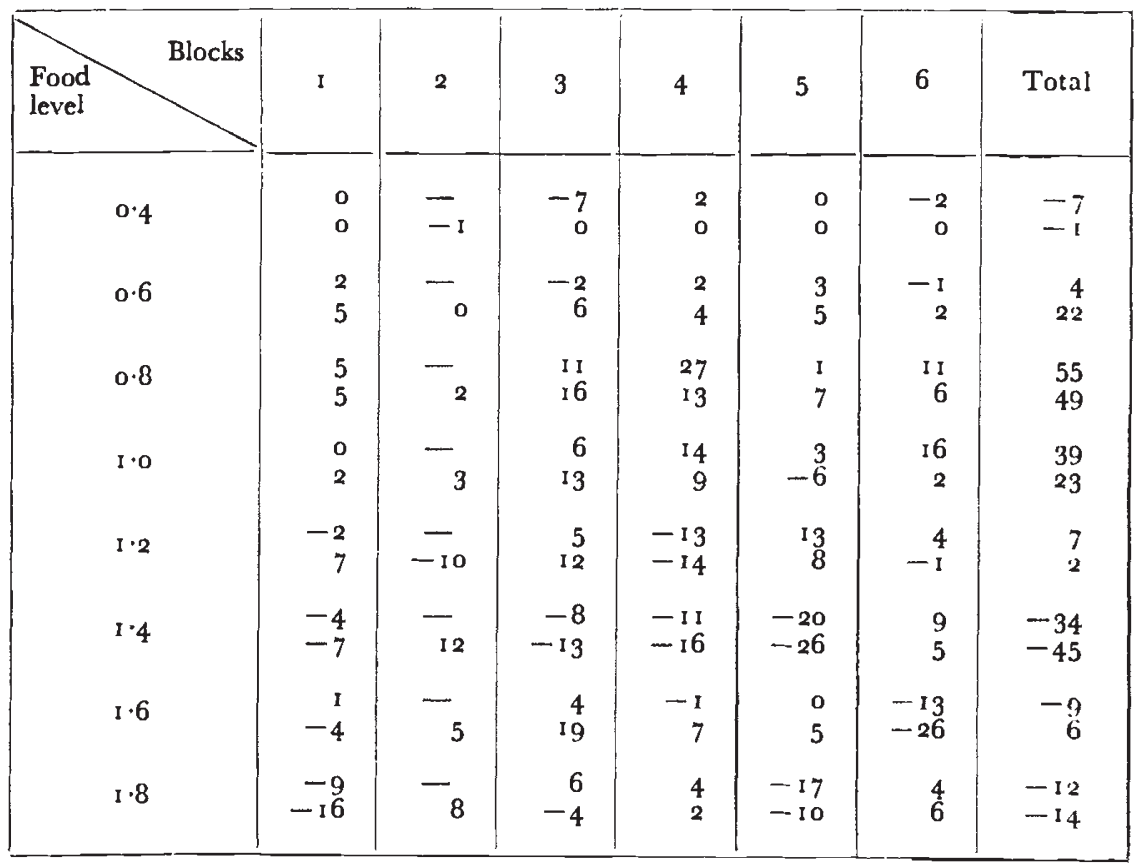

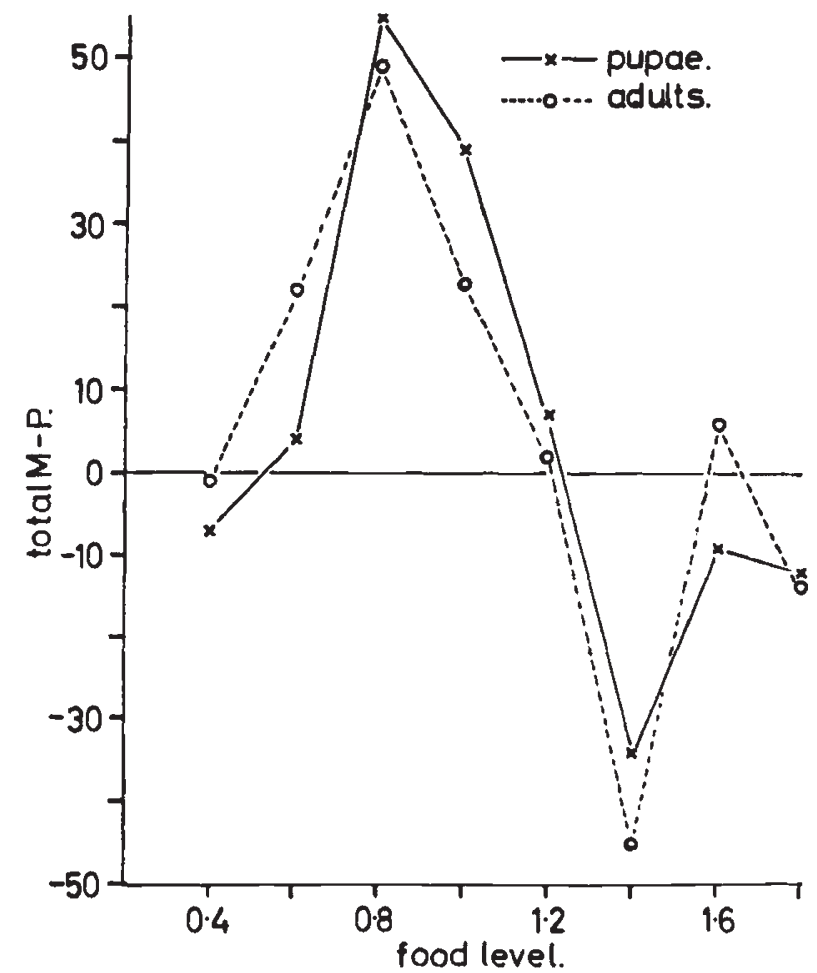

Fic. 5.-Observed relationship between total M-P values and food level for pupæ and adults over the critical range. 
food levels, blocks and food levels $\times$ blocks. The food levels SS can be partitioned into linear, quadratic and cubic components, the latter component providing a test for the expected cubic relationship between M-P value and food level.

Analyses of variance, partitioned in this way, of both pupal and adult results are shown in tables 3 and 4 .

TABLE 3

Analysis of variance of $M-P$ values (pupe)

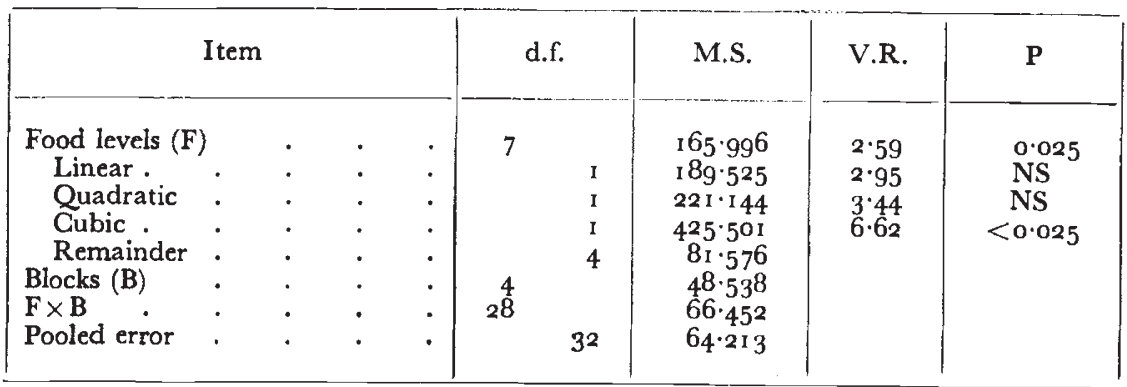

From table 3 it can be seen that the M-P values obtained for pupæ vary with food levels, and that the variation can be adequately described by a cubic regression $(\mathrm{P}<0.025)$. With the adult data (table 4), however, the variation of M-P with different food levels

TABLE 4

Analysis of variance of $M-P$ values (adults)

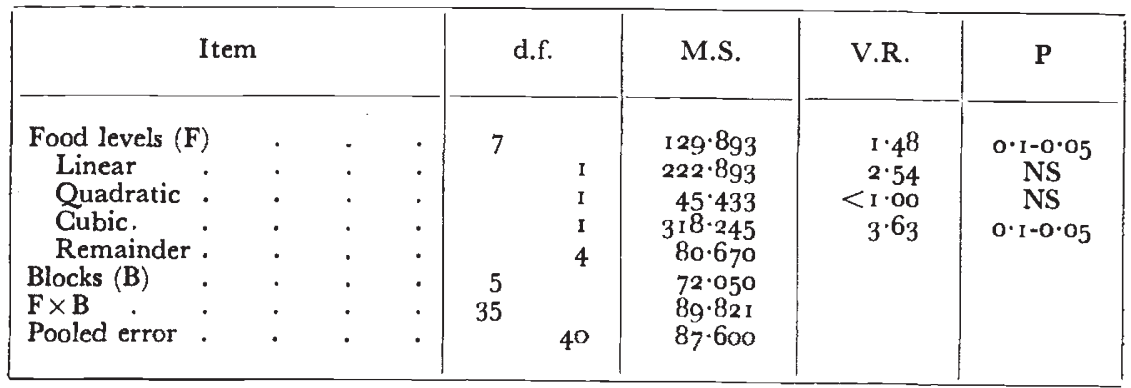

falls just short of significance, though the largest part of the SS for food levels again attaches to the cubic component.

There is then evidence of a cubic regression of M-P value on food level over the critical range in the adult results and strong evidence for such a relationship in the pupal data. Furthermore, the results agree with expectation in yet another way.

It was explained in the introduction that the cubic relationship between M-P values and food level was due to the stronger competitor, in this case vg6, having a higher M-P value at low food levels, 
while the weaker competitor, 2, has a large negative M-P value at high food levels. Reference to fig. 6 shows that this situation holds in the present case in which the M-P values from the adult viabilities have been plotted for each line separately.

It must be emphasised, however, that the error variance involved in such experiments is expected to be high. The critical food range is

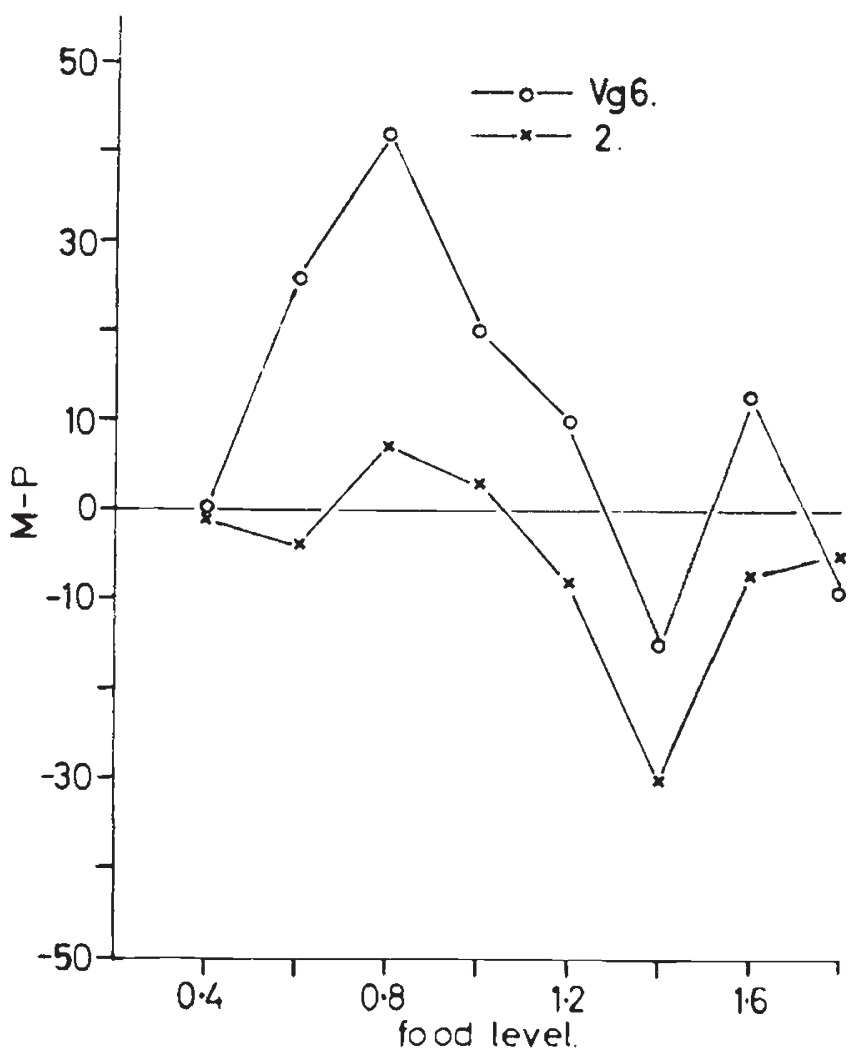

Fic. 6.-Observed M-P values of lines 2 and vg6 separately over the critical range.

small, hence viability will be greatly affected by small variations in the food supply. Because of the difficulty of ensuring that the yeast is well dispersed throughout the medium, there is likely to be much variation in the amount of yeast in tubes containing the same volume of medium. This problem of mixing the yeast also contributes to block heterogeneity.

\section{DISCUSSION}

It would appear from this experiment that there is a strong case for the hypothesis that competitive superiority, or inferiority, in obtaining food among Drosophila larvæ depends on the feeding rate. Further, this hypothesis has a high predictive value in connection with the relationship between total mixed culture superiority (or inferiority) 
and food supply. It has been shown that mixed cultures can produce a higher yield, as well as a lower yield, than pure cultures due to the action of competition alone.

This study, however, was of a very simple competitive situation and it would be useful to know whether the hypothesis is likely to hold in more complex cases. In order to discuss this it is necessary to consider in more general terms the possible outcomes of association between two strains or groups of organisms. Let us suppose that initially mixed cultures contain equal numbers of both strains, and we measure the difference in yield from mixed and pure cultures (M-P) for both strains separately.

Two possibilities exist. First both strains could be affected by the association in the same direction, i.e. both show an increase or a decrease in yield of a particular character. This relation can be described as,++ or - , - . The second possibility is that the two strains could be affected in different directions $(+,-)$ or only one strain affected $(+$, o or,- 0$)$.

The,++ effect could be due to some form of cooperation in which the presence of one strain benefits the other and vice versa. Symbiosis, of course, is an example of this. Alternatively, however, the two strains may not cooperate but merely fail to be restrictive members of each other's environment. By this it is meant that the two strains may have different specific requirements, such as an essential nutrient or an optimum light intensity at a certain time of the year, which limit the yield in pure culture. As each strain is represented by only half the number of individuals in mixed as in pure culture, there would be a greater share of the specific requirement to each individual. Thus both lines would obtain more of the limited resource and both would improve cf. Beardmore, I 963).

These two explanations can be distinguished by removing one or other of the competing strains from the mixed culture, so effectively halving the pure culture density of each line. Then, if cooperation is acting, a line will do no better at the new half density than it did in the original pure culture, since it no longer has the benefit of the other strain. However, if the second explanation is correct the lower density should result in a yield equal to that in a $50 / 5^{\circ}$ mixture of the two strains.

Similar explanations could be proposed for the - , - situation, the analogy to cooperation being mutual inhibition or antagonism, and the analogy to a deficiency of a specfic requirement, being an inhibitor in excess supply.

The second group of outcomes (,+-- , etc.) is somewhat more complex. The + , - situation must certainly be due to competition as defined in this text, the one strain improving and the other being depressed as a result of association. The existence of the,$+ o$ and -, o situations, although not demonstrable statistically, are none the less theoretical possibilities. They could result from competition, as 
was suggested in the present experiment, and also from a specific requirement possessed by only one of the lines. Such explanations based on the existence of specific requirements do not imply that competition is not occurring but that competition is within and not between the strains. This whole situation is of course complicated by all the possible interactions between the suggested causes of M-P differences. Hence it would seem advisable in discussing the results of any mixed culture experiments, to use terms which describe the outcome rather than the cause.

In any mixed culture experiment it may be difficult to decide whether or not competition is affecting the outcome. However, if competition alone is responsible for any differences between mixed and pure cultures, and the individuals within the groups are normally distributed with respect to a limited resource, then the effects described in this paper should occur over the critical range even with complex mixtures. It is likely, however, that in most such cases there will be competition for more than one resource, and the relative competitive abilities of the various competing lines may be different for each resource. It might then be unrealistic to expect the effects observed in the simple case of two lines to be manifested in more complex situations.

The experimental technique could obviously be improved in this case, to overcome heterogeneity due to difficulties in dispensing the medium. Also the predictive value of the theory could be increased by measuring the competitive gain (or loss) of food at each food level. It is reasonable to expect that the greater the volume of medium presented to the larvæ, the longer the feeding time will be. Thus, if the feeding rates of the two lines are different, the magnitude of the gain (or loss) of food by each line will also increase with food level, and not be constant as is assumed here. However, this will not fundamentally affect the M-P curve, and taking the average gain or loss may well be adequate.

\section{SUMMARY}

I. Competition, defined as "the endeavour of two (or more) individuals to gain the same particular thing, or to gain the measure each wants from a supply of a thing when that supply is not sufficient for both (or all)", has been studied using larvæ from two lines of Drosophila melanogaster, 2 and vg6, over a range of food levels which limit survival. Over this range, viability, measured as the proportion of larvæ either pupating or forming adults, increases from zero to a maximum in a sigmoid curve.

2. On the assumption that larval competitive ability depends on feeding rate, a method is described for estimating the food gained or lost by the competitively superior or inferior line, respectively, in mixed culture. This allows the viabilities of the two lines in mixed culture to be predicted from their viabilities in pure culture at any food level. 
3. The predicted viabilities show that the difference between the total yield of mixed and pure cultures (M-P) should follow a cubic regression over the range of food levels limiting viability.

4. An experiment designed to test this prediction is described. The expected cubic relation was found. Thus competition can of itself result in mixed cultures outyielding, as well as underyielding, pure cultures.

5. The relevance of these findings to more complex associations is discussed.

Acknowledgment.--This work was carried out during the tenure of an Agricultural Research Council Studentship.

\section{REFERENCES}

BAKKER, K. 1961. An analysis of factors which determine success in competition for food among larvæ of Drosophila melanogaster. Arch. Neerl, de Zool., r4, 200-281. BEARDMORE, J. A. 1963. Mutual facilitation and the fitness of polymorphic populations. The American Naturalist, 97, 69-74.

MATHER, K., AND COOKE, P. 1962. Differences in competitive ability between genotypes of Drosophila. Heredity, $17.2,381-407$.

milne, A. 1961. Definition of competition among animals. Symp. Soc. Exp. Biol., 15, Cambridge University Press.

PARK, T. 1948. Experimental studies of inter-species competition. I. Competition between populations of the flour beetles, Tribolium confusum Duval and Tribolium castaneum Herbst. Ecol. Monogr., r8, 265-308. 